\title{
The relationship of body condition indicators with the level of plasma cocaine and amphetamine regulated transcript and energy metabolism indicators in dairy cows
}

\author{
Krzysztof Młynek ${ }^{1}$, Beata Głowińska ${ }^{2}$, Ewa Salamończyk ${ }^{1}$ \\ ${ }^{1}$ Siedlce University of Natural Sciences and Humanities, Faculty of Natural Science, \\ Department of Cattle Breeding and Milk Evaluation, Siedlce, Poland \\ ${ }^{2}$ UTP University of Science and Technology, Faculty of Animal Breeding and Biology, \\ Department of Animal Physiology, Physiotherapy and Nutrition, Bydgoszcz, Poland
}

Received January 23, 2018

Accepted February 12, 2019

\begin{abstract}
The factors affecting the course of lactation and intensity of milk secretion include the condition and body weight, as well as chewing time. A little researched factor is also the cocaine and amphetamine regulated transcript (CART) which has been suggested to have an anorexigenic function. This study sought to examine the dependent indicators of condition and chewing time on daily milk yield assessment in the context of the concentration of CART, glucose and B-hydroxybutyrate (BHB) in blood. Higher CART levels contributed to shorter chewing time (min/day), lower body condition and lower body weight. Blood glucose concentration showed a stronger correlation with body weight and condition than with blood BHB concentration. An important practical aspect of the results is the relationship shown between CART and chewing time and the potential relation between daily milk production and chewing time. Importantly, the animals with lower daily milk production had relatively the highest concentration CART. This may suggest that this neuropeptide is indirectly involved in milk production, especially by shortening the chewing time. The obtained results help to better explain the mechanisms involved in milk secretion and the process of rumination and digestion. More research is required, but they also show important functions of other examined neuropeptides.
\end{abstract}

Chewing time, body weight, neuropeptide, milk production

Increasing milk yields of dairy cows more and more often disrupt their metabolic processes. In the first period after calving, this mostly concerns a decrease in rumen motility and excessive mobilization of energy reserves (Kováč et al. 2009) and changes in the profile of hormones participating in energy metabolism (Vargová et al. 2015). Research findings show that this often entails disruption of food ingestion and chewing. Little attention, especially during the first weeks of lactation, is paid to the role played by anorexigenic neuropeptides secreted in different segments of the digestive tract. Some of these, by regulating appetite, have an effect on the ingestion of food and chewing time (Hunter et al. 2004), determining the rumen metabolism and energy balance in cattle (Nikkhah 2011). The impact of this influence on many digestive functions is often observed in the neuroendocrine structures, which are related to the mechanisms of milk secretion control. Therefore, for high-producing cows it is expected that this impact may be critical to the processes that control milk secretion.

Satisfactory milk production is based on the feeding, amount of feed intake, and nutrient utilization, which depend largely on the chewing time and retention time in different segments of the digestive tract. These functions may be weakened by the anorexigenic action of the cocaine and amphetamine regulated transcript (CART). Its presence has been reported in the wall of the pyloric portion of the abomasum in cattle (Młynek et al. 2015) as well as in energy metabolic pathways in monogastric and laboratory animals (Rohner-Jeanrenaud et al. 2002; Wortley et al. 2004; Lucidi et al. 2005). Based on current knowledge, it may be hypothesized that higher concentrations of CART reduce

Address for correspondence:

Krzysztof Młynek

Department of Cattle Breeding and Milk Evaluation

Siedlce University of Natural Science and Humanities

Siedlce, Poland

http://actavet.vfu.cz/ 
appetite and increase the risk of excessive mobilization of fat reserves. This may impair liver metabolism and lead to excessive ketosis.

The aim of the experiment was to analyse how the connection between the cows' body weight, body condition, and chewing time affects the concentration of CART and selected blood metabolism indices, as evaluated in terms of the amount of milk produced per day in Polish Holstein-Friesian cows. The experimental hypothesis was that lower values of the studied indices would be obtained from cows with higher concentrations of anorexigenic $\mathrm{CART}$ in blood and a resulting reduction in milk production.

\section{Animals}

\section{Materials and Methods}

The experiment was conducted in the spring in a total of 60 Holstein-Friesian dairy cows. The general characteristics of the cows are presented in Table 1. The mean production age was 2.5 lactations. The milk yield production of the previous lactation (305-day) was $7256 \pm 3591$.

Table 1. Characteristic traits of production and body condition indicators, blood indices and chewing time in cows during lactation.

\begin{tabular}{lcccc}
\hline $\begin{array}{l}\text { Traits } \\
\mathrm{n}=284\end{array}$ & Means & Min. & Max. & SEM \\
\hline Day of lactation & 142 & 5 & 197 & 2.16 \\
Body weight (kg) & 532.9 & 423.6 & 692.7 & 2.93 \\
Daily milk production (1) & 32.5 & 15.9 & 43.5 & 0.37 \\
BCS (point) & 2.35 & 2.0 & 4.0 & 0.04 \\
Content in the blood: & & & 4.531 & 0.042 \\
$\quad$ Glucose (mmol/l) & 2.542 & 1.356 & 1.815 & 0.024 \\
\multicolumn{1}{c}{ BHB (mmol/1) } & 1.021 & 0.329 & 1.987 & 0.022 \\
CART (ng/ml) & 0.926 & 0.349 & 920.4 & 75.0 \\
CT (min/day) & 756.4 & 617.4 & & \\
\hline
\end{tabular}

BCS - body condition score; BHB - ß-hydroxybutyrate; CART - cocaine and amphetamine regulated transcript; CT - chewing time; SEM - standard error of the mean

\section{Housing and nutrition management}

Cows were kept in a free-stall barn with separate lying areas. Animals were milked by milking robots and fed in concentrated feeding stations. An automatic feed push-up robot was used at the feed bunk.

The diets were formulated according to INRA feeding standards (INRAtion Software for Ruminant Diet Calculation, version 2.03; DJ Group, Krakow, Poland). Roughage was prepared in the feed mixer, with maize silage, grass and lucerne haylage, straw (1 kg/animal/day) and a concentrate containing soybean and rapeseed meal, vitamin-mineral supplements, and buffering agents (ground limestone). During the first 100 days, the cows received additional glycerine as well as concentrate in pellet form from automatic feeders.

\section{Monitoring of the indicators}

Data on the characteristics of production, physiological indices such as body weight (BW), body condition score (BCS), biochemical blood indices such as B-hydroxybutyrate (BHB), glucose (GLU), CART, and chewing time (CT) were collected at 10, 40, 70, 100, and 150 days of lactation. In total, 284 (n) complete data sets were used for statistical calculations.

Transponders were used for identification of the cows in the system. Chewing time per day (min/day) was measured using noseband-sensor halters. Body weight was determined using a weighing platform on the floor of the milking stall (sensor system). Devices for measuring BM and CT were validated at 30-day intervals. Cows were evaluated for the amount of depot fat using a BCS ( 1 = emaciated to $5=$ obese). The BCS, BW, CT and amount of milk drawn were determined on the blood sampling day.

Energy metabolism was evaluated from the concentration of BHB and GLU in blood, and the level of CART was also determined. Samples were collected in the morning from the abdominal vein, on the day of BCS estimation. Tubes for GLU (with sodium fluoride; Medlab-Products, Poland), BHB and CART (with clot activator) were 
used. After collection, the blood samples were transported to laboratory on ice (approximately within $2 \mathrm{~h}$ ). Blood samples were then centrifuged at $1.500 \times \mathrm{g}$ at $4{ }^{\circ} \mathrm{C}$ for $20 \mathrm{~min}$. The isolates were stored at $-80{ }^{\circ} \mathrm{C}$ until analysis.

Plasma CART concentrations $(\mathrm{ng} / \mathrm{ml})$ were measured by enzyme immunoassay using bovine specific ELISA kit (EIAab, Wuhan, CN). Glucose concentration ( $\mathrm{mmol} / \mathrm{l})$ was determined in whole blood by the enzymatic method, using Randox kits (Randox Laboratories Ltd, Crumlin, UK).

\section{Statistical analysis}

To evaluate the effects of the selected factors (BW, BCS, and CT), statistical analyses with repeated measurements with Linear Mixed Models (LMM) were performed using Statistica 13.0. The analysis included the day of lactation as a covariate when factors were assessed using a covariance matrix. Correlation between the selected indicators was calculated using the variance-covariance matrix model $(P \leq 0.05)$.

\section{Results}

The data presented in Table 1 show the cows did not exhibit an increased energy deficit during the lactation period under study. Their GLU and BHB blood concentrations ranged from 1.356 to 4.531 and from 0.329 to $1.815 \mathrm{mmol} / 1$, respectively. During the analysed lactation period, the BW of cows averaged $532.9 \mathrm{~kg}$ (ranging from 423.6 to $692.7 \mathrm{~kg}$ ), and their mean BCS was 2.35 (from 2.0 to 4.0 ). The CT averaged $756.4 \mathrm{~min} /$ day, but varied considerably between 617.4 and $920.4 \mathrm{~min} /$ day.

Table 2. General characteristics of traits and correlation coefficients for chewing time with production traits, BCS and blood indices.

\begin{tabular}{|c|c|c|c|c|c|c|}
\hline \multirow{3}{*}{$\begin{array}{l}\text { Traits } \\
\mathrm{n}=284\end{array}$} & \multicolumn{3}{|c|}{$\mathrm{CT}(\mathrm{min} / \mathrm{d}$} & \multirow{3}{*}{ SEM } & \multirow{3}{*}{$P$ value } & \multirow{3}{*}{$\begin{array}{c}\text { Correlation } \\
\mathrm{CT} \times\end{array}$} \\
\hline & I & II & III & & & \\
\hline & 167 & 71 & 46 & & & \\
\hline CT (min/day) & 711.9 & 802.1 & 847.4 & 4.4 & 0.001 & - \\
\hline Body weight (kg) & 516.7 & 548.9 & 554.7 & 2.8 & 0.019 & $0.383 *$ \\
\hline Daily milk production (1) & 30.3 & 35.1 & 36.2 & 0.4 & 0.017 & $0.517^{*}$ \\
\hline BCS (point) & 2.19 & 2.54 & 2.65 & 0.04 & 0.011 & $0.379 *$ \\
\hline \multicolumn{7}{|l|}{ Content in blood: } \\
\hline GLU (mmol/l) & 2.753 & 2.575 & 2.199 & 0.021 & 0.012 & $-0.389 *$ \\
\hline BHB (mmol/l) & 2.499 & 3.233 & 3.103 & 0.038 & 0.005 & $-0.345^{*}$ \\
\hline CART (ng/ml) & 1.695 & 1.169 & 1.065 & 0.037 & 0.001 & $-0.644^{*}$ \\
\hline
\end{tabular}

$* P \leq 0.05$; BCS - body condition score; CT - chewing time; GLU - glucose; BHB - ß-hydroxybutyrate; CARTcocaine and amphetamine regulated transcript; SEM - standard error of the mean

The results obtained for the changes in the analysed indicators depending on the time spent chewing are shown in Table 2 . The CT was significantly correlated to BW and BCS. The animals with a longer CT were at the same time characterized by a higher BW and stronger body condition which was confirmed with correlation analysis that produced the values of 0.383 and 0.379 , respectively $(P \leq 0.05)$. It is of note that increased CT was more strongly correlated with the amount of milk produced per day $(0.517 ; P \leq 0.05)$. Analysis of the results for biochemical components of blood (Table 2) demonstrated that a longer CT was associated with lower GLU and BHB concentrations. A lower blood concentration of CART was found in animals with a longer CT. This trend may indicate that a longer CT resulting in a lower CART concentration allows the body to have a more efficient energy metabolism. The changes shown in the tables for the blood components were confirmed by the obtained coefficients of correlation. For the GLU and BHB concentrations, the correlations with CT were not very strong ( -0.389 and $-0.345 ; P \leq 0.05)$; but they were stronger for CART $(-0.644 ; P \leq 0.05)$. The contribution of CART to regulating the CT reflex here most probably resulted from suppression of appetite. This suggests that animals 
Table 3. General characteristics of traits and correlation coefficients for BCS with production traits, blood indices and chewing time.

\begin{tabular}{|c|c|c|c|c|c|c|}
\hline \multirow{3}{*}{$\begin{array}{l}\text { Traits } \\
\mathrm{n}=284\end{array}$} & \multicolumn{3}{|c|}{ BCS (point) } & \multirow{3}{*}{ SEM } & \multirow{3}{*}{$P$ value } & \multirow{3}{*}{$\begin{array}{c}\text { Correlation } \\
\text { BCS } \times\end{array}$} \\
\hline & $\mathrm{I}(<2.5)$ & II $(2.5-3.4)$ & $\mathrm{III}(>3.5)$ & & & \\
\hline & 169 & 98 & 23 & & & \\
\hline BCS (point) & 1.96 & 2.83 & 3.50 & 0.04 & 0.011 & - \\
\hline Body weight (kg) & 522.3 & 544.5 & 546.7 & 2.8 & 0.023 & $0.278^{*}$ \\
\hline Daily milk production (1) & 31.0 & 34.5 & 35.2 & 0.4 & 0.012 & $0.309 *$ \\
\hline \multicolumn{7}{|l|}{ Content in blood: } \\
\hline Glucose (mmol/1) & 1.986 & 2.542 & 3.104 & 0.039 & 0.007 & $0.461 *$ \\
\hline $\mathrm{BHB}(\mathrm{mmol} / \mathrm{l})$ & 1.161 & 0.853 & 0.655 & 0.024 & 0.004 & $-0.471 *$ \\
\hline CART (ng/ml) & 1.651 & 1.196 & 1.130 & 0.016 & 0.002 & -0.529 \\
\hline CT (min/day) & 740.4 & 776.5 & 793.8 & 4.4 & 0.003 & $0.379 *$ \\
\hline
\end{tabular}

$* P \leq 0.05$; BCS - body condition score; BHB - $\beta$-hydroxybutyrate; CART - cocaine and amphetamine regulated transcript; CT - chewing time; SEM - standard error of the mean

Table 4. General characteristics of traits and correlation coefficients for body weight with daily milk production, BCS, blood indices and chewing time.

\begin{tabular}{|c|c|c|c|c|c|}
\hline \multirow{3}{*}{$\begin{array}{l}\text { Traits } \\
\mathrm{n}=284\end{array}$} & \multicolumn{2}{|c|}{ Body weight (kg) } & \multirow{3}{*}{ SEM } & \multirow{3}{*}{$P$ value } & \multirow{3}{*}{$\begin{array}{l}\text { Correlation } \\
\qquad \mathrm{BM} \times\end{array}$} \\
\hline & $\mathrm{I}(\leq 531)$ & II $(>531)$ & & & \\
\hline & $(n=142)$ & $(n=142)$ & & & \\
\hline Body weight (kg) & 494.9 & 568.0 & 2.8 & 0.020 & - \\
\hline Daily milk production (1) & 30.4 & 34.5 & 0.4 & 0.019 & $0.394 *$ \\
\hline BCS (point) & 2.21 & 2.51 & 0.04 & 0.025 & $0.279 *$ \\
\hline \multicolumn{6}{|l|}{ Content in the blood: } \\
\hline Glucose (mmol/1) & 2.023 & 3.075 & 0.039 & 0.002 & $0.721 *$ \\
\hline BHB (mmol/l) & 1.129 & 0.912 & 0.034 & 0.009 & $-0.282 *$ \\
\hline CART (ng/ml) & 1.634 & 1.289 & 0.029 & 0.001 & $-0.491 *$ \\
\hline $\mathrm{CT}$ (min/day) & 733.9 & 778.8 & 4.5 & 0.002 & $0.483^{*}$ \\
\hline
\end{tabular}

$* P \leq 0.05$; BCS - body condition score; BHB - $\beta$-hydroxybutyrate; CART - cocaine and amphetamine regulated transcript; CT - chewing time; SEM- standard error of the mean

with a higher CART concentration in their blood can absorb fewer nutrients. This caused these animals to have poorer BCS (Table 3 ) and lower body weight (Table 4).

In the case of biochemical blood analysed in the context of BCS (Table 3), the trends were similar only for BHB and CART. The negative correlations ( -0.471 and -0.529$)$ obtained in these two cases indicate that greater BCS values (groups 2 and 3 - BCS above 2.5) were most often paralleled by lower concentration of these compounds in blood. The opposite trend was observed for the blood GLU concentration (0.461) which was markedly higher in animals with a higher BCS (groups 2 and 3). In animals from these groups, CT was most often clearly longer, averaging $785.2 \mathrm{~min} /$ day. These groups also shared a similar daily production of 34.81 on average. This suggests that the BCS of cows depends to a similar extent on the CT $(0.379 ; P \leq 0.05)$ and the intensity of milk secretion per day (0.309; $P \leq 0.05)$.

The analysed indicators of daily milk production showed the strongest correlation with the cow's body mass (Table 4). The observed tendency was confirmed by the difference 
in the amount of milk produced ( 4.11 on average) and $\mathrm{r}=0.394(P \leq 0.05)$. The BM was also found to have a significant effect on the CT $(-0.483 ; P \leq 0.05)$. Animals with a higher BW had a longer CT by $44.9 \mathrm{~min} /$ day, which averaged $778.8 \mathrm{~min} /$ day. This is relevant because of the pre-treatment of feed, a process which improves nutrient utilization and intake, thus increasing the intake of energy that determines BCS. However, the smallest effect, confirmed by a significant difference $(P \leq 0.05)$ of $0.3 \%$, was noted for BCS. In this case, the correlation was weak $(0.279 ; P \leq 0.05)$. The data in Table 4 show that BW had the strongest effect on blood GLU concentration. The difference between animals representing both $\mathrm{BW}$ groups averaged $1.052 \mathrm{mmol} / \mathrm{l}$, with $\mathrm{r}=0.721(P \leq 0.05)$. A slightly weaker effect of BW was found for CART concentration. However, as for GLU, in heavier animals with higher BW, blood had a higher content of this neuropeptide, by $0.345 \mathrm{ng} / \mathrm{ml}$ on average $(0.491 ; P \leq 0.05)$. In the case of BHB, blood from heavier animals had a lower concentration of it by an average of $0.217 \mathrm{mmol} / \mathrm{l}$, with $\mathrm{r}=-0.282(P \leq 0.05)$.

\section{Discussion}

The intensity of milk secretion during the first weeks of lactation is the principal determinant of its course as well as the body's homeostasis (Nikkhah et al. 2008). Kováč et al. (2009) have shown a strong relationship between some indicators of energy metabolism and peptides mediating the immune response of the cow's body in the period around calving. They also showed that in cows with a higher concentration of non-esterified fatty acids indicating greater mobilization of lipids, a higher concentration of acute phase proteins was more frequently observed.

Disruption of homeostasis in lactating cows is largely limited by normal BCS and long enough CT, which is conducive to maximizing the nutrient intake from feed (Goldhawk et al. 2009). According to Jiang et al. (2017), by influencing ruminal physiology and metabolism, these factors also have an effect on the amount of feed intake. In this respect, an interesting field of research is the role of CART. It is important to conduct research aimed at understanding the association of ruminal physiology (Rohner-Jeanrenauda et al. 2002) and metabolic processes (Lucidi et al. 2005) with the perception of appetite and the amount of food eaten.

In cattle, CART secretion is located in the pyloric section of the abomasum (Młynek et al. 2015). Studies suggest that this neuropeptide is closely connected with energy metabolism, in cattle as well. In this regard, the trends observed in our study for BCS are consistent with the findings of Młynek et al. (2015), who showed lower accumulation of adipose tissue in the carcasses of animals whose abomasums had a larger number of CART structures in the pyloric section. This may affect the body condition (Keyun and Yanyun 2007). Furthermore, Nikkhah et al. (2008) demonstrated that lower feed intake (reduced appetite) may perturb the energy homeostasis by causing clear changes to the concentration of GLU, urea and ketone bodies. This trend is confirmed by our results obtained for GLU and BHB as well as CT, which to a certain extent may characterize the strength of appetite. Attention should also be drawn to the role of anorexigenic CART, which in our study proved to be strongly associated (more so than the other indicators) with the CT and the amount of subcutaneous adipose tissue (BCS). Especially in the first period of lactation in high-yielding dairy cows, the regulation of energy metabolism is subject to sudden changes through mobilization of lipids from adipose tissue. Chelikani et al. (2003) indicate that during that time, these mechanisms induce leptin involved in the body condition. It is noteworthy at this point that the analysed CART is strongly involved in the regulation of energy metabolism (Keyun and Yanyun 2007). In the context of endogenous regulators of energy metabolism as well as gastrointestinal performance (Nikkhah et al. 2008), the effect of CART reported in our study may have a significant effect on the course and rate of energy metabolism. These authors showed that the level of BCS was dependent 
on metabolism associated with GLU levels and higher insulin activity. Our findings of low GLU concentration in animals with the lowest BCS, the highest concentration of anorexigenic CART, and the shortest CT, may be indicative of an energy deficit induced by inadequate nutrient utilization. Similar tendencies were reported by Nikkhah et al. (2008).

In terms of the body's energy reserves, body weight is an important factor associated with the metabolic potential in high-yielding cows (Clauss et al. 2009). However, its relationship with daily milk production is not completely understood. Our results for the connection between the daily milk yield, BCS, and body mass correspond with the findings of Clauss et al. (2009), who showed that a sudden decrease in BCS (loss of body weight) during the first weeks of lactation adversely affects the persistence of milk yield. Our results obtained for the indicators of energy metabolism may suggest that in cows with lower body weight, the effect of lactation persistency may be more at risk because the higher level of anorexigenic CART shortens the CT by suppressing appetite. Another benefit of prolonged CT, according to Jiang et al. (2017), is better hydration and buffering of ingested feed, which has a positive effect on rumen metabolism. Compared to the studies cited above, our results indicate a more pronounced association between $\mathrm{BW}$ and $\mathrm{CT}$, because cows with lower BW were characterized by clearly shorter CT, which in their case could have an adverse effect on the amount of nutrient intake, and thus on lower blood GLU concentration, more rapid mobilization of energy reserves (higher BHB concentration) and a weaker body condition. It is supposed that this effect was largely augmented by the relationships that we show with the concentration of anorexigenic CART. Studies of Vargova et al. (2015) indicate the dependence of some hormones on BCS. These results were confirmed by positive values of the correlation coefficient with leptin (0.360) and insulin (0.232) and a negative correlation between BCS and ghrelin (-0.257). These data indicate that leptin, ghrelin and insulin concentrations clearly affect changes in BCS.

In light of the function of endogenous regulators of energy metabolism as well as daily milk production and BCS, our results are consistent with those of Chelikani et al. (2003). They showed that the relationship between milk secretion and BCS can be dependent on the GLU concentration, which along with leptin is involved in energy metabolism pathways. Chelikani et al. (2003) showed that during the first period of lactation, the influence of blood GLU and lipid concentration on the stimulation of leptin secretion is less important, concluding that during that time leptin expression and release were inhibited by the growth hormone. In light of this study, our results suggest that in addition to the identified endogenous substances involved in regulation of energy metabolism, CART remains an important co-regulator of these processes. In the study by Vargová et al. (2015), it was shown that changes in energy profile indices (including BHB and GLU) in cows after calving play a physiological role in the formation of BCS. Depending on the level of hormones (leptin, ghrelin or insulin), they can induce higher feed intake, which is beneficial for milk production and the physiological condition of cows in the first lactation period.

The results of our research indicate that the anorexigenic effect of CART, which mediates the regulation of fat accumulation and BW (Wortley et al. 2004; Młynek and Janiuk 2013), may significantly contribute to feed intake, and thus indirectly influence the intensity and persistence of milk secretion. This effect was reported by Asnicar et al. (2001) who showed that rats deprived of the gene regulating the production of CART ingested more feed. As a result, the animals showed increased BW and greater amounts of accumulated adipose tissue, as indicated also by Hunter et al. (2004). Młynek et al. (2015) demonstrated that bulls in which more CART structures were observed in the pyloric section of the abdomen, had a significantly thinner layer of external fat and less fat carcasses. Existing knowledge allows us to guess how CART engages in pancreatic activity and regulation of plasma glucose. Research conducted by Wierup and Sundler (2006) on the clarification of the putative role of CART in islet hormone release revealed 
that CART potentiates glucose-stimulated insulin secretion from clonal b-cells in the rat. The possible contribution of CART to energy metabolism pathways that regulate the GLU concentration was also suggested by Arciszewski et al. (2008) for sheep. Their study showed that this neuropeptide is involved in regulating pancreatic insulin secretion. This fact is relevant because insulin secreted in the pancreas has the function of regulating blood GLU concentration and is directly related to food ingestion (Rohner-Jeanrenaud et al. 2002). This is thus another major function of this neuropeptide, particularly given that this function can be strengthened in the presence of CART in the structures of the stomach (Młynek et al. 2015).

The association of CT with blood CART concentration and the effect of this relationship on the body condition, body mass and productivity in cows, as observed in our study, is important in light of the findings of Davidowa et al. (2005), who showed a significant effect of food restriction on CART gene expression and the amount of neuropeptide secretion. These results seem relevant from the viewpoint of our study, because the shorter CT, which is generally associated with the amount of feed eaten, could influence the expression and amount of CART secreted in the stomach. This hypothesis is supported by Bannon et al. (2001) who reported that administration of exogenous CART to rats clearly suppresses their appetite reflex. The fact that CART contributes to mechanisms regulating BW and rate of adipose tissue deposition has been confirmed by Młynek and Janiuk (2013) for cattle and by Wortley et al. (2004) and Asnicar et al. (2001) for monogastric laboratory animals.

In the context of CT, the feed given to high-yielding dairy cows is highly important for ingestion behaviour, which according to Maulfair et al. (2010) has a fundamental effect on the production of saliva and of buffering sodium bicarbonate. As a consequence, this is important for rumen fermentation processes (Nikkhah et al. 2008) and gastrointestinal motility (Dias et al. 2011). In light of the above studies, appetite-suppressing CART, by shortening the $\mathrm{CT}$, may reduce the particle size and moisture of feed, thus adversely affecting ruminal fermentation and limiting the availability of nutrients. These results correspond with the findings of Weckerly (2013) who showed that the BW of cows is associated, among other factors, with the amount of feed intake. The research by these authors is consistent with the results of our study, in which heavier animals exhibited longer CTs and at the same time lower blood CART concentrations.

The results obtained lead to the conclusion that in the development of body mass and condition, CT is directly involved, which is significantly affected by the level of the anorexigenic function of CART. Most probably its concentration in blood has an indirect effect on the body's energy metabolism. The anorexigenic role of CART, associated in our study with shorter CT, is confirmed by the relatively strong correlations of blood indices with CT. With regard to the most important practical aspect of the amount of milk produced per day, our results show that CART is indirectly involved in this process. This can be concluded from the magnitude of the correlation between milk production and CT. At the same time, it was found that shorter CT were accompanied by higher blood concentrations of CART.

The results of our study extend the current knowledge on endogenous factors involved in the energy metabolism of ruminants and can be used to improve production efficiency with regard to the feeding of cows.

\section{References}

Arciszewski MB, Całka J, Majewski M 2008: Cocaine- and amphetamine-regulated transcript (CART) is expressed in the ovine pancreas. Ann Anat 190: 292-299

Asnicar MA, Smith DP, Yang DD, Heiman ML, Fox N, Chen Y F, Hsiung HM, Koster A 2001: Absence of cocaine- and amphetamine-regulated transcript results in obesity in mice fed a high caloric diet. J Endocrinol 142: 4394-4400 
Bannon A, Seda J, Carmouche M, Francis JM, Jarosinski MA, Douglass J 2001: Effects of cocaine- and amphetamine regulated transcript (CART) peptides in mice: CART 42-89 and CART 49-89 differ in potency and activity. J Pharmacol Exp Ther 299: 1021-1026

Chelikani PK, Keisler DH, Kennelly JJ 2003: Response of plasma leptin concentration to jugular infusion of glucose or lipid is dependent on the stage of lactation of Holstein cows. J Nutr 133: 4163-4171

Clauss M, Nunn C, Fritz J, Hummel J 2009: Evidence for a tradeoff between retention time and chewing efficiency in large mammalian herbivores. Comp Biochem Phys A 154: 376-382

Davidowa H, Li Y, Plagemann A 2005: The main effect of cocaine- and amphetamine-regulated transcript (CART) peptide on hypothalamic neuronal activity depends on the nutritional state of rats. Neuro Endocrinol Lett 26: 29-34

Dias AS, Patino HO, Lopez S, Prates E, Swanson KC, France J 2011: Relationships between chewing behavior, digestibility, and digesta passage kinetics in steers fed oat hay at restricted and ad libitum intakes. J Anim Sci 89: 1873-1880

Goldhawk C, Chapinal N, Veira DM, Weary DM, von Keyserlingk MAG 2009: Prepartum feeding behavior is an early indicator of subclinical ketosis. J Dairy Sci 92: 4971-4977

Hunter RG, Philpot K, Vicentic A, Dominguez G, Hubert GW, Kuhar M J 2004: CART in feeding and obesity. Trends Endocrin Met 15: 454-459

IZ-INRA 2001: IZ-INRA Standards of cattle, sheep and goat nutrition. National Research Institute of Animal Production, Krakow, Poland. Developed by INRA 1988

Jiang FG, Lin XY, Yan ZG, Hu ZY, Liu GM, Sun YD, Liu XW, Wang ZH 2017: Effect of dietary roughage level on chewing activity, ruminal $\mathrm{pH}$, and saliva secretion in lactating Holstein cows. J Dairy Sci 100: 2660-2671

Keyun Q, Yanyun C 2007: Central CART gene delivery by recombinant AAV vector attenuates body weight gain in diet-induced-obese rats. Regul Peptides 140: 21-26

Kováč G, Tóthová C, Nagy O, Seidel H, Konvičná J 2009: Acute phase proteins and their relation to energy metabolites in dairy cows during the pre- and postpartal period. Acta Vet Brno 78: 441-447

Lucidi P, Murdolo GD, Loreto C, Parlanti N, De Cicco A, Fatone C 2005: Metabolic and endocrine effects of physiological increments in plasma ghrelin concentrations. Nutr Metab Cardiovass 15: 410-417

Maulfair DD, Zanton GI, Fustini M, Heinrichs AJ 2010: Effect of feed sorting on chewing behavior, production, and rumen fermentation in lactating dairy cows. J Dairy Sci 93: 4791-4803

Młynek K, Janiuk I 2013: Detection of cocaine and amphetamine regulated transcript in the abomasum of slaughtered bulls with different daily body weight gains. Acta Vet Brno 82: 253-257

Młynek K, Janiuk I, Oler A, Maj M, Borkowska L 2015: Correlation between the cocaine - and amphetamineregulated transcript in the pyloric section of the abomasum and fat deposition in bulls' carcasses. Acta Vet Brno 84: $337-342$

Nikkhah A, Furedi CJ, Kennedy AD, Crow GH, Plaizier JC 2008: Effects of feed delivery time on feed intake, rumen fermentation, blood metabolites and productivity of lactating cows. J Dairy Sci 91: 1-12

Nikkhah A 2011: Bioscience of ruminant intake evolution: feeding time models. Adv Biosci Biot 2: 271-274

Rohner-Jeanrenaud F, Craft L S, Bridwell J, Suter TM, Tinsley FC, Smiley DL, Burkhart DR, Statnick MA, Heiman ML, Ravussin E 2002: Chronic central infusion of cocaine- and amphetamine-regulated transcript (CART 55-102): effects on body weight homeostasis in lean and high-fat-fed obese rats. Int J Obesity 26: 143-149

Vargová M, Petrovič V, Konvičná J, Kadaši M, Zaleha P, Kováč G 2015: Hormonal profile and body condition scoring in dairy cows during pre partum and post partum periods. Acta Vet Brno 84: 141-151

Weckerly FW 2013. Conspecific body weight, food intake, and rumination time affect food processing and forage behavior. J Mammal 94: 120-126

Wierup N, Sundler F 2006: CART is a novel islet regulatory peptide. Peptides 27: 2031-2036

Wortley KE, Chang GQ, Davydova Z, Fried SK, Leibowitz SF 2004: Cocaine- and amphetamine -regulated transcript in the arcuate nucleus stimulates lipid metabolism to control body fat accrual on a high-fat diet. Regul Peptides 117: 89-99 